\title{
Superplasticizer and Shrinkage Reducing Admixture Dosages for Microfine Cement in Grout Systems
}

\author{
Md Shamsuddoha, Götz Hüsken, Wolfram Schmidt, Hans-Carsten Kühne, and Matthias Baeßler \\ Safety of Structures Division, Federal Institute for Materials Research and Testing (BAM), Unter den Eichen 87, 12203 Berlin, Germany
}

\begin{abstract}
Grouts have numerous applications including crack repair as maintenance in construction industries. Microfine cements are intensively used for high strength mortar and grout products. They are ideal for injection grouting in structural repair. Such grouts should have suitable rheological properties to be injectable, especially those used in repair and rehabilitation. The use of superplasticizers (SP) in these products is thus becoming increasingly crucial to achieve favorable workability and viscosity properties. A difficulty in such grouts is the plastic shrinkage due to finer particles used. It is thus necessary to determine optimum SP and shrinkage reducing admixture (SRA) dosages for a microfine cement based grout. In this study, a saturation dosage was decided from two Polycarboxylate ether (PCE) based SPs in relation to neat cement using slump flow and rheological parameters. A range of grout mixtures was formulated containing micro silica (MS) and fly ash (FA), and tested for suitable rheological and mechanical parameters. Based on the results, a grout mixture with MS and FA was selected to determine optimum SRA content. According to the results, a SP dosage of 3\% by weight of neat cement is sufficient to achieve saturation. The grout material including MS and FA can produce comparable properties to neat cement grout. MS is found to improve compressive strength within the range considered, whereas a higher FA content provides favourable rheological properties. Finally, a SRA dosage of $4 \%$, which could reduce the shrinkage by about $43 \%$ after $28 \mathrm{~d}$ days, is determined for the grout system.
\end{abstract}

\section{Introduction}

Grouting is intensively used for void filling, sealing joints, soil stabilization, and repair of masonry and structural elements [1-3]. Suitable grouts should retrieve the continuity, cohesion and strength of the damaged structures without altering their shape and load-bearing behavior. Hence, grouting is an indispensable part of structural maintenance of concrete and composite structures over their lifetimes. The design of the grout as well as the method of its applications must satisfy a series of performance requirements including nature of defects. The efficiency of such grouting depends on the material rheology, injectability, and mechanical strength.

Cement is one of the multifaceted construction materials due to its demonstrated areas of usage. Grouting is such a branch of application. A special type of cement: Microfine cements, which are also known as ultrafine cement, were intensively used for structural applications including oil-well cementing and highpressure grouting [4-6]. Microfine cements were also used for structural remediation $[7,8]$. These cements are ideal candidates for structural grouting due to their superior effects on rheology and hardened properties in comparison to coarser ordinary Portland cements. However, the cement itself is sometimes not sufficient to achieve desirable properties. In such situations, special admixtures and supplementary cementitious materials are introduced.

Depending on the method and conditions of grout processing, rheological properties of the grout need to be adjusted [9]. High strength grouts require low water content, which reduces workability and increases viscosity. For this reason, superplasticizers (SPs) are often used to modify the workability of mixture. Shrinkage of cementitious materials is a phenomenon that may cause cracks on structural or non-structural elements. Since grouts used in repair fill voids, shrinkage at hardened stage is critical. In structural concrete, cracking may be reduced by appropriate reinforcement, which is almost impossible in grout systems. The reinforcement does not reduce shrinkage, but can prevent cracks from widening. The use of expansive cements is a possible way to reduce shrinkage [10]. Expansive cements produce expansion by formation of ettringite, which is less effective to control early age cracking. The use of shrinkage reduction admixtures (SRA) is another way to reduce shrinkage [11]. The use of supplementary cementitious materials is also common to reduce costs and to modify properties. The most commonly used supplements are micro silica (MS), fly ash (FA), metakaolin (MK), and ground granulated blast-furnace 
slag (GGBS) $[12,13]$. A combination of these ingredients, when used, requires quantification through experimental investigation.

This study proceeded as a series of successive tests, which were carried out in stages involving workability and mechanical properties. A saturation dosage between two SPs were decided. Further, two supplementary cementitious materials: MS and FA were used and varied to find appropriate ranges. At the end, SRA contents were varied to determine a suitable dosage. Finally, a range of these ingredients is outlined for a typical grout for structural rehabilitation, from where further detailed tests could continue.

\section{Experimental details}

\subsection{Material properties}

A microfine hydraulic binder was used in this study. It has a particle size distribution with $\mathrm{D}_{95}<12 \mu \mathrm{m}$ and BET specific surface of $2200 \mathrm{~m}^{2} / \mathrm{kg}$. The specific density is 3.14. The cement complies with the requirements given by EN 197-1 [14] for CEM I 52.5 R LA SR with $\mathrm{C}_{3} \mathrm{~A}$ content $<3.5 \%$. Initially, two polycarboxylate ethers (PCE) based superplasticizers were used due to their advantages over lignosulphonates plasticizers [15]. For commercial confidentially, they are named as SP-A and SP-B. A summary of their properties is given in Table 1.

Table 1. Properties of superplasticizers.

\begin{tabular}{lll}
\hline Properties & SP-A & SP-B \\
\hline Physical form & Liquid & Liquid \\
Color & Brown & Brown \\
Sp. Density $\left[\mathrm{kg} / \mathrm{m}^{3}\right]$ & $1100 \pm 30$ & $1060 \pm 20$ \\
$\mathrm{pH}$ & $7.0 \pm 1.0$ & $6.5 \pm 1.0$ \\
\hline
\end{tabular}

The density and $\mathrm{pH}$ values are measured at $20^{\circ} \mathrm{C}$. Both of these plasticizers confirm to DIN EN 934-2 [16]. Two supplementary cementitious materials (SCM): micro silica and fly ash were selected for modifying the properties of neat cement grout. A silica fume with specific density of 2.207 and $\mathrm{D}_{95}=35 \mu \mathrm{m}$ was used. A class F fly ash with higher silica content of $58 \%$ was used. It has a specific density of $2.320 \mathrm{~g} / \mathrm{cm}^{3}$ and $\mathrm{D}_{95}=150 \mu \mathrm{m}$. The SRA is a blend of aliphatic alcohols and glycols with an inorganic carrier. It is in powder form with a relative density of $0.470 \mathrm{~g} / \mathrm{cm}^{3}$.

\subsection{Test program}

The test program was carried out in three stages. The sequential processes can be demonstrated as Figure 1. At first, one SP and its saturation dosage was selected using rheological properties. Neat cement was used in this stage and SPs were varied between $1-5 \%$ by weight of cement for simplicity. A constant water cement ratio of 0.30 by weight of neat cement (bwoc) was used in these tests. Slump was determined at 10, 20, 30, and 40 minutes after the beginning of mixing for this stage. Moreover, viscosity parameters were also measured after 10 minutes after the end of mixing.

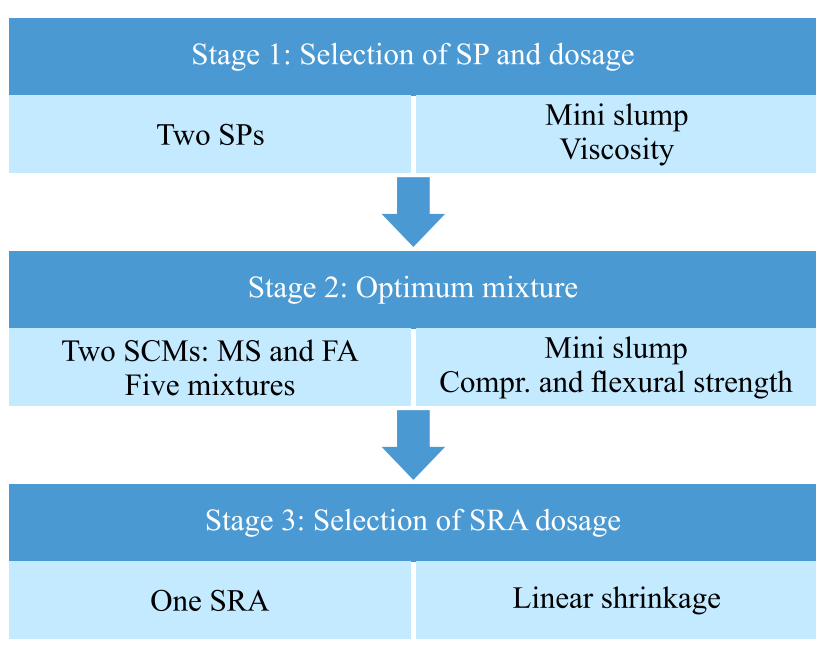

Figure 1. Summary of test program.

Using the saturation SP dosage, a test series was formulated containing two SCMs in the next stage. Five test mixes shown in Table 2 were formulated and investigated. A water cement ratio $(0.32$ bwoc $)$ was used in this stage. Mechanical properties after 28 days in addition to rheological properties were also investigated and a suitable mixture was decided. Slump was determined after 10 minutes after the beginning of mixing. In the last stage, an optimum SRA dosage was selected through testing of plastic shrinkage. The SRA dosages were varied from $0-5 \%$ bwoc.

Table 2. Mix designs for investigating optimum mixture.

\begin{tabular}{ccc|ccccc}
\hline \multirow{3}{*}{ Mix } & \multicolumn{2}{c|}{$\begin{array}{l}\% \text { Volume } \\
\text { replacement }\end{array}$} & \multicolumn{4}{|c}{ Volume $\left(\mathrm{kg} / \mathrm{m}^{3}\right)$} \\
\cline { 2 - 8 } & MS & FA & CEM & MS & FA & Water & SP \\
\hline 1 & 0 & 0 & 477.6 & 0 & 0 & 479.9 & 42.4 \\
2 & 0 & 8 & 439.4 & 0 & 38.2 & 479.9 & 42.4 \\
3 & 3 & 0 & 463.3 & 14.3 & 0 & 479.9 & 42.4 \\
4 & 6 & 8 & 410.8 & 28.7 & 38.2 & 479.9 & 42.4 \\
5 & 3 & 16 & 386.9 & 14.3 & 76.4 & 479.9 & 42.4 \\
\hline
\end{tabular}

\subsection{Preparation and test setup}

Mixing was carried out using an intensive mixer. The dry mix contents were first mixed for 1 minute at $400 \mathrm{rpm}$. Then, water and half of the SP were added first and mixed for 1 minute at $400 \mathrm{rpm}$. Afterward rest half of the SP was added and mixed for another minute at the same speed. A pause in mixing for 1.5 minutes was taken to scrape the surface mix back to container. The mixing was then continued for 1 minute at $400 \mathrm{rpm}$ and, finally, for 2 minutes at $800 \mathrm{rpm}$. The total mixing time amounts to 7.5 minutes.

Paste flow was measured using Haegermann cone with a height of $60 \mathrm{~mm}$, lower diameter of $100 \mathrm{~mm}$, and upper diameter of $70 \mathrm{~mm}$ conforming to DIN EN 1015-3 [17]. No vibration was used due to the fact that grouts 
should inherently have a self-compacting behavior. Viscosity was measured using a Schleibinger Viskomat NT. A special double gap rotational cell, which was developed by Vogel [18], was used, which enables fluidin-fluid shear and thus minimizes wall effects. The measurement of the apparent viscosity was carried out by analyzing the response of mixes under the rotational velocity ramps given in Figure 2 . The viscosity was measured for shear response during downward ramp, which occurs at around 10 minutes from the end of mixing.

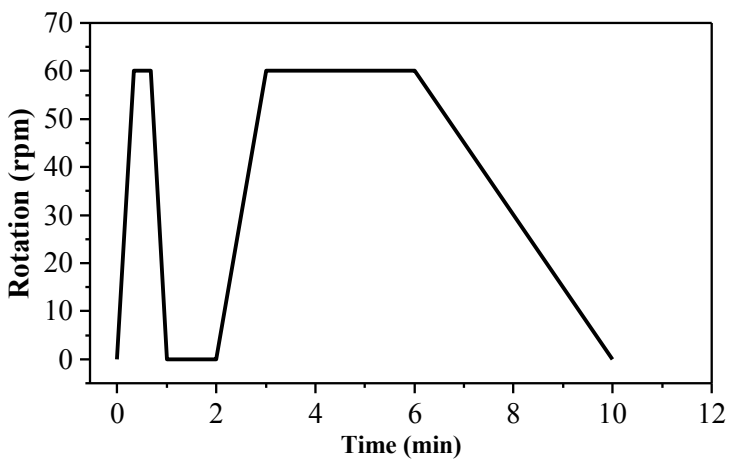

Figure 2. Rotational ramps for viscosity measurement.

Compression and flexural tests were carried out conforming BS EN 196-1 [19], where 40x40x160 mm prismatic samples were used. Specimens for linear shrinkage and strength were removed from the molds after 24 hours. Linear shrinkage was determined conforming to DIN EN 12617-4 using prismatic specimens [20]. Specimens were cured in a controlled air-conditioned environment at 50\% relative humidity and $23^{\circ} \mathrm{C}$, whereas compressive and flexural specimens were cured at submerged condition at the same temperature for 28 days prior to testing. Figure 3 shows tests are being carried out.
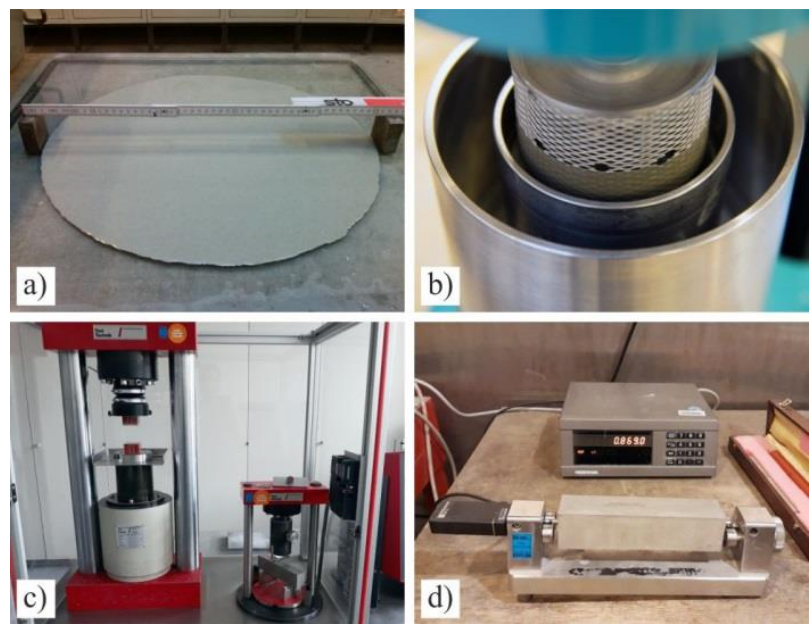

Figure 3. Details of tests carried out: a) slump flow, b) rheometer, c) strength, d) linear shrinkage.

\section{Results and discussion}

Since the study was carried out in three successive stages, the results are also presented accordingly.

\subsection{Selection of SP and dosage}

The effect of time and SP dosages on flow is shown in Figure 4. It is to be noted here that the base of the flow cone is $100 \mathrm{~mm}$. The variation in flow diameter within first 40 minutes for a constant SP dosage is minimal with a maximum range of $50 \mathrm{~mm}$, indicating that the plasticizers are stable within that period. The flow diameter is $100 \mathrm{~mm}$ for both SP-A and SP-B content of $1 \%$, which means there is no flow in the paste. The flow diameter reaches around $375 \mathrm{~mm}$ with $2 \%$ of SP-A and increase by about $25 \mathrm{~mm}$ over 40 minutes, whereas there is no significant increase in flow for $2 \%$ of SP-B. $3 \%$ SPA resulted in a comparable slump to that of $2 \%$, which remained consistent over next 40 minutes.

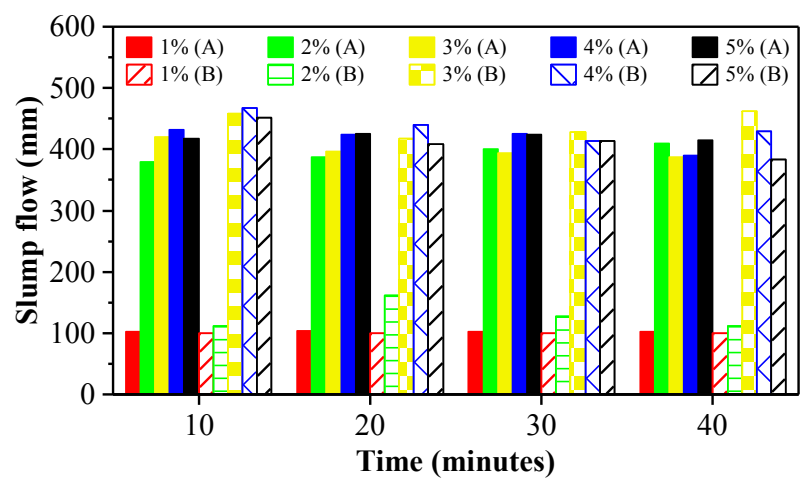

Figure 4. Effect of time and SP dosage on slump flow.

To further investigate the flow performance of SPs, Figure 5 is drawn for slump flows at 20 minutes. This comparison shows that once an optimum content is reached the flow is either consistent or slightly higher due to additional water. According to the results, $2 \%$ is the saturation dosage for SP-A. On the other hand, it takes about 3\% SP-B to attain about $400 \mathrm{~mm}$ slump, which remained steady up to $5 \%$ with slight increase up to about $450 \mathrm{~mm}$. The maximum slump for both SPs can be considered comparable once they achieved saturation. However, to draw a conclusion, further comparison with viscosity measurement is necessary.

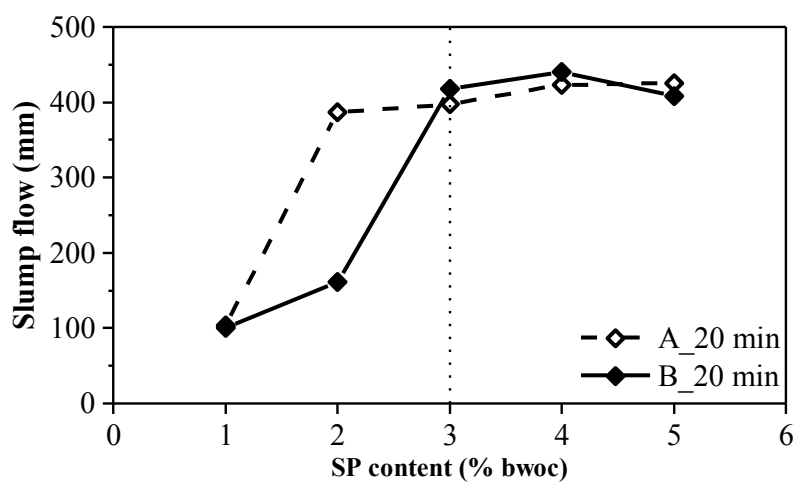


Figure 5. Quantification of saturation dosage using slump flow.

Comparison of shear stresses is shown in Figure 6. The comparison is drawn up to dosage of $5 \%$. Contents lower than $3 \%$, which are not presented here implies that those mixtures are too viscous to be tested by the rheometer. In general, SP-B provides lower stress than that of SP-A. The ratio of stresses in SP-B to SP-A for a constant SP dosage is nearly 0.5 , which indicates that SP$\mathrm{B}$ is expected to provide a much injectable mixture for practical application. Relating Figure 5 and Figure 6, it can be decided that SP-B is the plasticizer for superior rheological properties and should be selected for further investigation at a dosage of $3 \%$ bwoc. It must also be added that the saturation point of SP-B may occur at any point between $2-3 \%$. However, it can be assumed that it has enough charge to saturate potential mixtures containing SCMs.

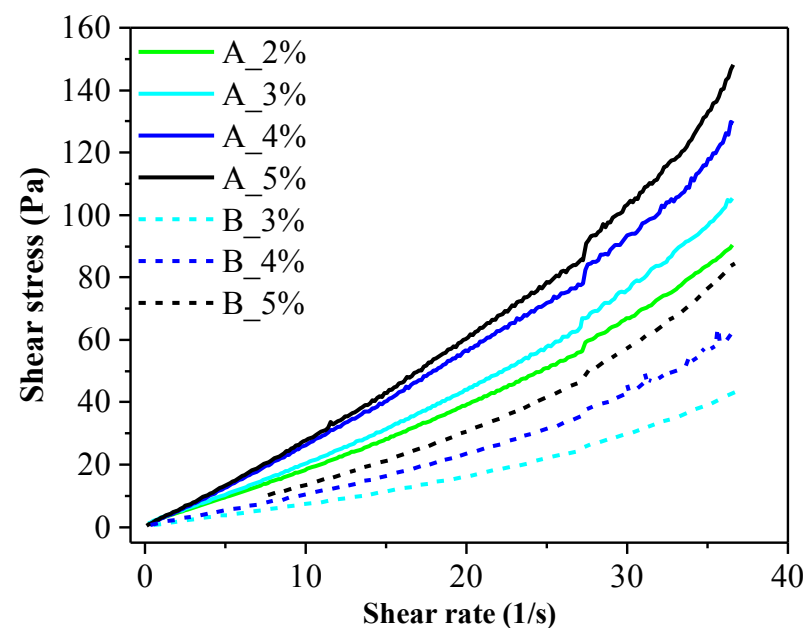

Figure 6. Effect of SP dosages on shear stress.

The shear stress increment is nonlinear in relation to shear rate opposed to that observed in a Newtonian fluid. Shear thickening effect is observed within the rate considered. Interesting to note that the stresses increase when SP dosages are increased. This is probably because of excess SP, not absorbed at the surface of cement particles, remaining in solution and increasing the viscosity of the interstitial fluid and thus increasing the plastic viscosity of the cement paste [21-23]. The localized effect of this retardation can be even such that the higher SP dosage (5\%) eventually result in formation of agglomerates in the paste immediately after mixing probably due to phase separation. Similar incompatibility between cement and admixture was discussed when low water and high admixture were used [24].

\subsection{Selection of optimum mixture}

The summary of the results from tests carried out at this stage are given in Table 3. The slump diameter varies within $568-610 \mathrm{~mm}$. The compressive and flexural strength vary within the ranges of $103-123 \mathrm{MPa}$, and $4.6-13.5 \mathrm{MPa}$, respectively. The results suggest that, despite replacements by $\mathrm{SCMs}$, comparable slump and strengths are achievable in comparison to neat cement.

Some simple comparisons can be drawn among the mixtures based on the results. Mix 5 with higher fly ash provides the highest slump. The fact that the slump diameter increases with an increase in FA aligns with the argument related to the morphological nature of fly ash, which suggests that fly ash reduces the filling water and has stronger lubricating role [25]. Mix 3 with 3\% MS provides the highest compressive strength, however lowest flexural strength. Addition of micro silica was also reported to increase the strength, but up to an optimum level of 10\% [26]. Moreover, Mix 4 and Mix 5 with higher FA provides higher flexural strength. These comparisons suggest that fly ash is advantageous for slump and flexural strength, whereas micro silica is beneficial for compressive strength but near the $3 \%$ margin. Depending on these facts, a mix containing $4 \%$ MS and 15\% FA can be selected to expect a grout material that has advantageous slump property and strength. These comparisons are presented here based on simple experimental/empirical observations. Detailed investigations with more mixtures are necessary to further define the relations.

Table 3. Summary of slump flow and mechanical properties.

\begin{tabular}{cccc}
\hline Mix & Slump (mm) & Comp. Str. (MPa) & Flex. Str. (MPa) \\
\hline 1 & 568 & 104 & 6.2 \\
2 & 577 & 114 & 9.2 \\
3 & 567 & 123 & 4.6 \\
4 & 570 & 117 & 13.5 \\
5 & 610 & 103 & 11.0 \\
\hline
\end{tabular}

\subsection{Selection of SRA dosage}

The effect of SRA dosages on mass loss due to water evaporation from hardened specimens with and without SRA is given in Figure 7. The reference mixture contains $4 \% \mathrm{MS}$ and $15 \% \mathrm{FA}$ that has been selection in the previous section for superior properties. The mass loss ranges within $6-7 \%$ for the mixtures tested. The results suggest that, in general, mass loss increased due to increase in SRA dosages. This trend does align with the finding of previous studies $[27,28]$, where SRA did not reduce the water evaporation from concrete when exposed to unsaturated air; rather remained closely aligned. This phenomenon cannot be related to the common analogy that SRA reduce capillary tension caused by the formation of water menisci developed in capillary pores, which is accountable for the shrinkage inside the cement paste $[11,29]$. Hence, the mass loss is higher in specimens with SRA - probably due to the reduction in the surface tension of the pore water, which resulted in a higher drying rate at the relative humidity (RH) of $50 \%$; compensating common analogy. Also curing condition was attributed to significant effect on shrinkage [27, 30]. Hence, it may be the low relative humidity that caused higher water loss. Apart from chemical shrinkage, it is well known that drying shrinkage and self-desiccation produce a decrease in the 
relative humidity in the pore system, which is responsible for part of shrinkage deformations. It was reported to reduce the internal relative humidity related to sealed curing at a range of $0.95-0.85$ at about 28 days [11, 31].

The shrinkage measurement began after 24 hours, which was selected as the reference point. Chemical shrinkage at very early age is normally much higher than autogenous shrinkage [13, 32]. Such shrinkage is of critical importance for practical applications. Hence, autogenous shrinkage is prioritized in this discussion. Drying shrinkage is thus also included within the autogenous shrinkage.

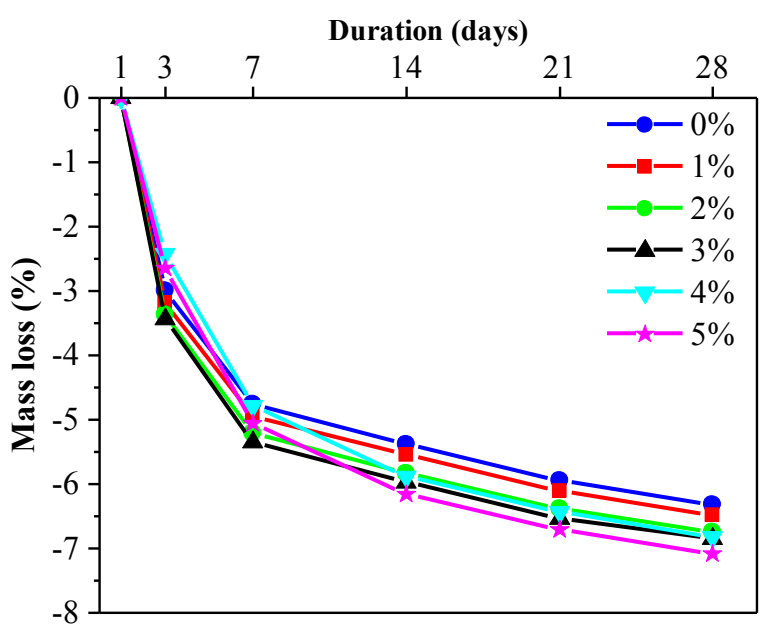

Figure 7. Effect of SRA dosages on mass loss over time.

Figure 8 shows effects of SRA dosages and duration on linear shrinkage. Each shrinkage value presented here is an average value obtained from six specimens. The shrinkage is nearly linear up until 7 days. Beyond 7 days, the trend suggests a diminishing effect. However, the plateau is not achieved indicating that there is still potential for shrinkage in the future, which was also observed for autogenous shrinkage [33]. This is due to the addition of SCMs with pozzolanic properties, especially fly ash, which is activated at later stage of hydration.

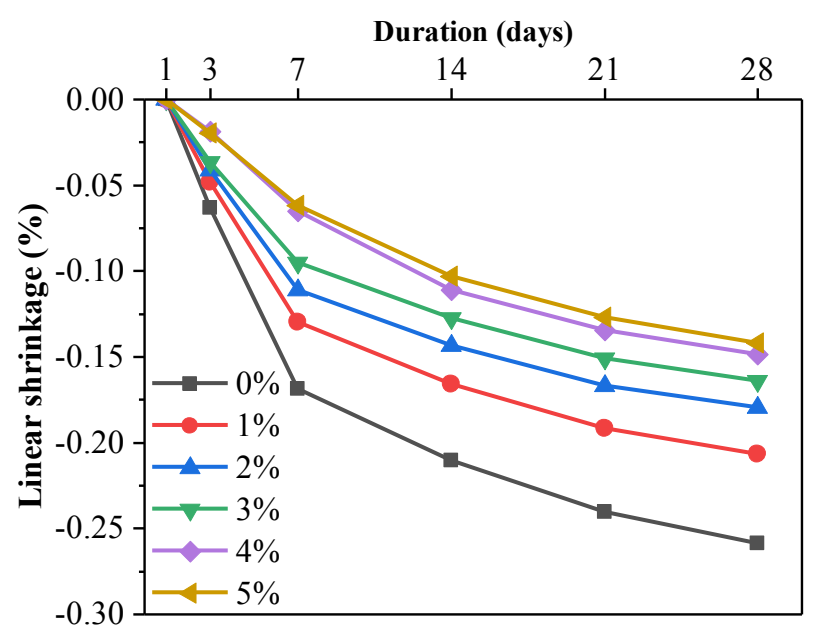

Figure 8. Effect of SRA dosages on shrinkage over time.
The shrinkage after 28 days is about $0.26 \%$. This is high compared to previous studies on a range of cement pastes [32, 34]. Several factors can contribute in this phenomenon. One reason may be the low $\mathrm{RH}$ curing in light of capillary tension approach [35]. Another factor may be the microfine cement, which is known to provide higher shrinkage compared to coarser ordinary Portland cement due to fineness and accelerated hydration caused more contraction phase of C-S-H gel [36-38]. Besides, microsilica was also attributed to higher autogenous shrinkage [39]. Although fly ash had positive effect on shrinkage for certain fly ashes, the adverse effect was also observed [40].

The shrinkage is reduced by about $45 \%$ for SRA dosage of $5 \%$. However, the reduction is less effective beyond $4 \%$, which provides about $43 \%$ reduction. Hence, this content can be considered optimum for the mixture considered. However, inclusion of such high volume of SRA may change the rheological properties necessitating modification in mix design to suit in situ applications.

\section{Conclusions}

At first, tests were conducted to determine a saturation SP dosage by increasing the SP content by weight for a microfine cement using rheological properties. Based on the SP dosage, five grout mixes with varied micro silica (MS) and fly ash (FA) contents were formulated and investigated for fresh and hardened properties. A mix design was formulated based on the properties aiming to superior rheological parameters and higher strength properties. Finally, linear shrinkage was investigated for determining a suitable SRA dosage for the grout system. The following conclusions can be drawn:

- Both SPs investigated for the neat cement grout provide comparable spread flow, however SP-B provides much favorable viscosity at a dosage of $3 \%$ bwoc. Once saturation is attained, a higher dosage negatively affects the shear stress.

- In general, an increased MS resulted in higher compressive strength and lower flexural strength. Slump flow and flexural strength increased with increasing fly ash content, whereas compressive strength reduced.

- A dosage of $4 \%$ is found optimum to reduce shrinkage by about $43 \%$, beyond which the reduction in shrinkage is negligible.

\section{Acknowledgement}

This study was undertaken under the LeBeWind project carried out in Federal Institute for Materials Research and Testing (BAM), Berlin. This project is funded by the Federal Ministry for Economic Affairs and Energy (BMWi), Germany.

\section{References}

1. C. Vipulanandan, in Proceedings of Geo-Logan '97 conf., GSP 66, ASCE 337 (1997).

2. N. P. Gil, Constr. Repair 10, 24-26 (1996). 
3. M. Mollamahmutoğlu and E. Avci, KSCE J. Civ. Eng. 19, 2041-2050 (2015).

4. W. J. Clarke and A. C. McNally, in Proceedings of Low Permeability Reservoirs Symposium and Exhibition, Society of Petroleum Engineers 291-298 (1993).

5. D. MacEachern and S. C. Young, Oil Gas J. 90, 4951 (1992).

6. E. Samari, D. L. T. Scott and D. Dalrymple, in Proceedings of 11th Symposium on Improved Oil Recovery, Part 2, Society of Petroleum Engineers 153-159 (1998).

7. K. L. Harris and B. J. Johnson, presented at the SPE Mid-Continent Gas Symposium, Amarillo, Texas, (1992).

8. K. H. Khayat, G. Ballivy and M. Gaudreault, Can. J. Civ. Eng. 24, 405-418 (1997).

9. J. Gołaszewski and J. Szwabowski, Cem. Concr. Res. 34, 235-248 (2004).

10. S. Nagataki and H. Gomi, Cem. Concr. Compos. 20, 163-170 (1998).

11. D. P. Bentz, M. R. Geiker and K. K. Hansen, Cem. Concr. Res. 31, 1075-1085 (2001).

12. B. Lothenbach, K. Scrivener and R. D. Hooton, Cem. Concr. Res. 41, 1244-1256 (2011).

13. M. C. G. Juenger and R. Siddique, Cem. Concr. Res. 78, 71-80 (2015).

14. Cement. Composition, specifications and conformity criteria for common cements, European Committee for Standardization, BS EN 197-1 (2011).

15. D. Nagrockiene, I. Pundienè and A. Kicaite, Constr. Build. Mater. 45, 324-331 (2013).

16. Admixtures for concrete, mortar and grout - Part 2: Concrete admixtures - Definitions, requirements, conformity, marking and labelling, Deutsches Institut für Normung e. V., EN 934-2 (2012).

17. Methods of test for mortar for masonry - Part 3: Determination of consistence of fresh mortar (by flow table), Deutsches Institut für Normung e. V., DIN EN 1015-3 (2007).

18. R. Vogel, Concr. Plant + Concr. Technol. BFT01/2008, 124-126 (2008).

19. Methods of testing cement - Part 1: Determination of strength, European Committee for Standardization, BS EN 196-1 (2005).

20. Products and systems for the protection and repair of concrete structures test methods Part 4:
Determination of shrinkage and expansion, Deutsches Institut für Normung e. V., DIN EN 12617-4 (2002).

21. H. B. Bey, J. Hot, R. Baumann and N. Roussel, Cem. Concr. Compos. 54, 17-20 (2014).

22. K. H. Khayat, Cem. Concr. Compos. 20, 171-188 (1998).

23. T. Kawai and T. Okada, ACI Spec. Pub. 119, 583 604 (1989).

24. S. Kubens, Interaction of cement and admixtures and its influence on rheological properties Göttingen: Cuvillier Verlag, (2010).

25. A. Wang, C. Zhang and W. Sun, Cem. Concr. Res. 33, 2023-2029 (2003).

26. A. Allahverdi and S. Salem, Ceram.-Silikáty 54, 65-71 (2010).

27. M. Collepardi, A. Borsoi, S. Collepardi, J. J. Ogoumah Olagot and R. Troli, Cem. Concr. Compos. 27, 704-708 (2005).

28. A. B. Ribeiro, A. Gonçalves and A. Carrajola, Mater. Struct. 39, 179-187 (2006).

29. N. S. Berke, L. Li, M. C. Hicks and J. Bae, ACI Spec. Pub. 217, 37-50 (2003).

30. K.-B. Park, in Proceedings of The third international research seminar, eds. B. Persson and G. Fagerlund, Lund University 93-101 (2002).

31. B. Persson, Mater. Struct. 30, 293-305 (1997).

32. E.-i. Tazawa, S. Miyazawa and T. Kasai, Cem. Concr. Res. 25, 288-292 (1995).

33. S.-H. Kang, S.-G. Hong and J. Moon, Cem. Concr. Res. 108, 20-30 (2018).

34. P. Lura, O. M. Jensen and K. v. Breugel, in Proceedings of The third international research seminar, eds. B. Persson and G. Fagerlund, Lund University 127-137 (2002).

35. P. Lura, O. M. Jensen and K. van Breugel, Cem. Concr. Res. 33, 223-232 (2003).

36. J. Hogancamp and Z. Grasley, Cem. Concr. Compos. 83, 405-414 (2017).

37. S. Li, F. Sha, R. Liu, Q. Zhang and Z. Li, Constr. Build. Mater. 153, 965-974 (2017).

38. D. P. Bentz, E. J. Garboczi, C. J. Haecker and O. M. Jensen, Cem. Concr. Res. 29, 1663-1671 (1999).

39. M. H. Zhang, C. T. Tam and M. P. Leow, Cem. Concr. Res. 33, 1687-1694 (2003).

40. L. Wu, N. Farzadnia, C. Shi, Z. Zhang and H. Wang, Constr. Build. Mater. 149, 62-75 (2017). 